\title{
Photodimerization of Arenediynes
}

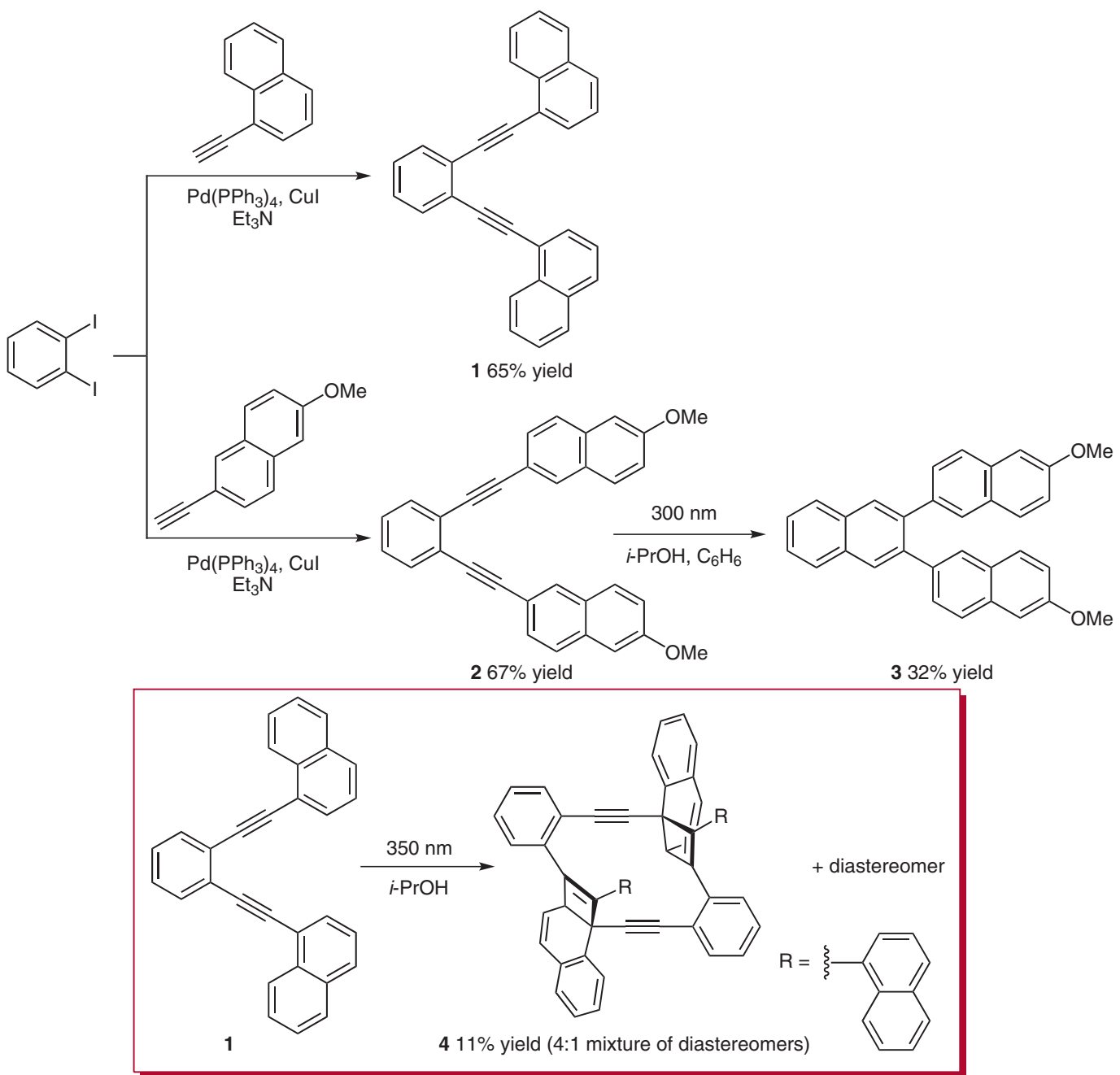

Significance: Cyclic enediynes as well as terminal acyclic enediynes are well known to undergo photochemical $C^{1}-C^{6}$ cycloaromatization. The authors explored the reactivity of naphthalenyl-substituted arenediynes ( $\mathbf{1}$ and $\mathbf{2}$ ). While the methoxysubstituted derivative $\mathbf{2}$ undergoes a photoBergman cyclization upon irradiation at $300 \mathrm{~nm}$, 1 shows no formation of $C^{1}-C^{6}$ or $C^{1}-C^{5}$ under these conditions. Irradiation of $\mathbf{1}$ at $350 \mathrm{~nm}$, however, yields a photodimerized product (4).

sYNFACTS Contributors: Timothy M. Swager, Jan M. Schnorr Synfacts 2011, 10, 1077-1077 Published online: 20.09.2011 Dol: 10.1055/s-0030-1261210; Reg-No.: S10111SF
Comment: The tandem [2+2] photocyclization yields two products in a 4:1 ratio. The structure of the major product (4) was determined by X-ray crystallographic analysis. Based on NMR studies, the authors suggest that the minor product is a diastereomer of 4 